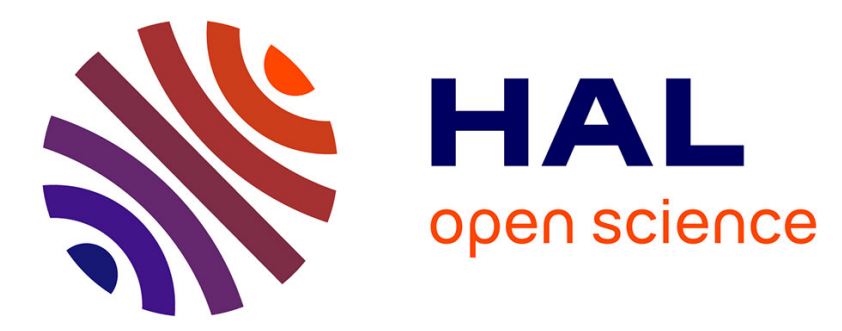

\title{
Data Justice through the Prism of Information Politics and Resource Injustice: A Case Study from Hyderabad's Urban Frontier
}

Loraine Kennedy, Ashima Sood, Debdatta Chakraborty, Ram Mohan Chitta

\section{- To cite this version:}

Loraine Kennedy, Ashima Sood, Debdatta Chakraborty, Ram Mohan Chitta. Data Justice through the Prism of Information Politics and Resource Injustice: A Case Study from Hyderabad's Urban Frontier. 2019. halshs-02319895

\section{HAL Id: halshs-02319895 \\ https://shs.hal.science/halshs-02319895}

Preprint submitted on 27 Dec 2019

HAL is a multi-disciplinary open access archive for the deposit and dissemination of scientific research documents, whether they are published or not. The documents may come from teaching and research institutions in France or abroad, or from public or private research centers.
L'archive ouverte pluridisciplinaire HAL, est destinée au dépôt et à la diffusion de documents scientifiques de niveau recherche, publiés ou non, émanant des établissements d'enseignement et de recherche français ou étrangers, des laboratoires publics ou privés. 


\section{Development Informatics}

\section{Working Paper Series}

The Development Informatics working paper series discusses the broad issues surrounding digital data, information, knowledge, information systems, and information and communication technologies in the process of socio-economic development.

Paper No. 78

\section{Data Justice through the Prism of Information Politics and Resource Injustice: $A$ Case Study from Hyderabad's Urban Frontier}

LORAINE KENNEDY, ASHIMA SOOD, DEBDATTA CHAKRABORTY \& RAM MOHAN CHITTA

2019

Published in collaboration with, and with the financial support of, the University of Manchester's Sustainable Consumption Institute and Canada's

International Development Research Centre

Published Centre for Development Informatics

by: $\quad$ Global Development Institute, SEED

University of Manchester, Arthur Lewis Building, Manchester, M13 9PL, UK Email: cdi@manchester.ac.uk Web: $\quad$ http://www.cdi.manchester.ac.uk

View/Download from:

http://www.gdi.manchester.ac.uk/research/publications/di/ 


\section{Table of Contents}

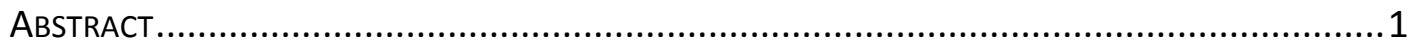

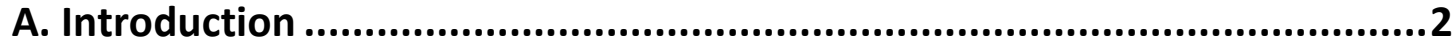

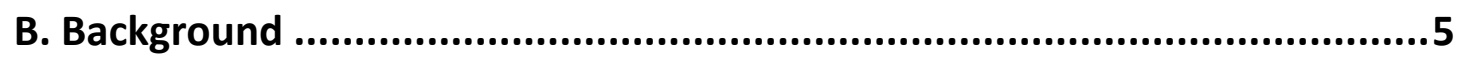

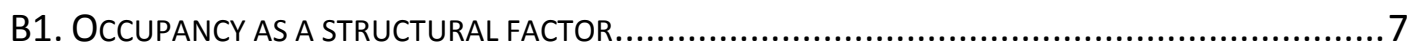

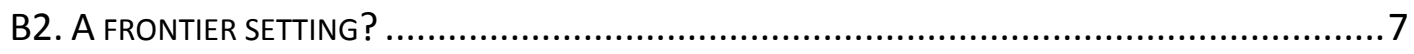

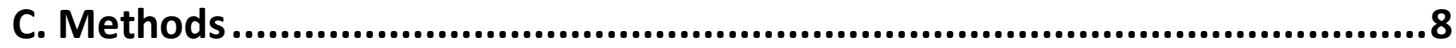

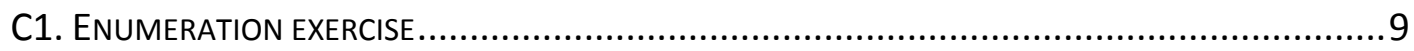

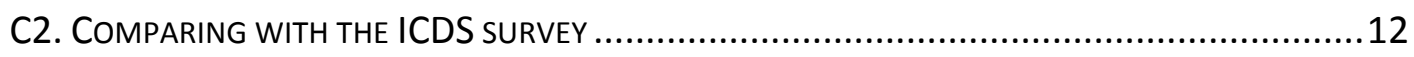

D. Findings.........................................................................13

D1. DATAFICATION PROCESSES ARE INFLUENCED BY WIDER STRUCTURES OF POWER, WHICH MEDIATE

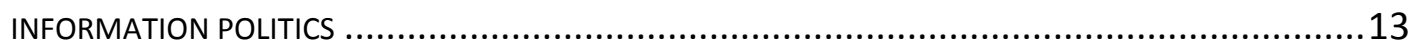

D2. THE ASSESSMENT OF DOWNSTREAM EFFECTS SHAPES RECEPTIVITY TO UPSTREAM ACTIVITIES, BUT

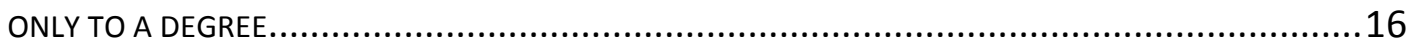

D3. DIGITAL AUDIO-VIDEO TECHNOLOGIES ARE INCREASINGLY AVAILABLE IN THE BASTI, BUT THEY HAVE NOT DISRUPTED THE REGULATION OF INFORMATION FLOWS BY POWERFUL ACTORS .............18

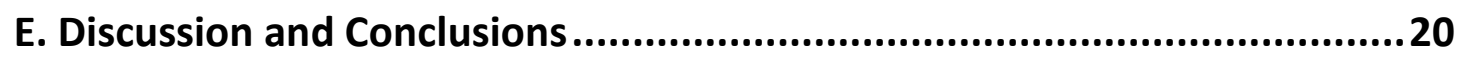

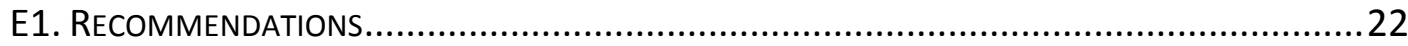

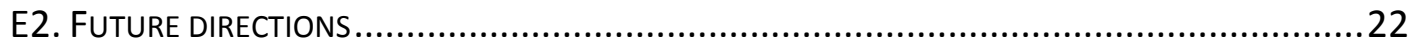

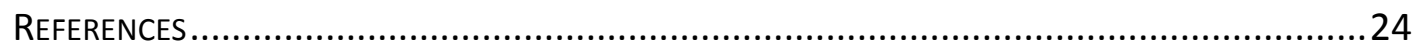

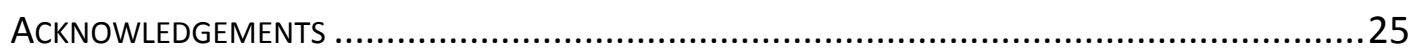

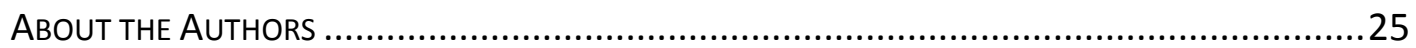




\title{
Data Justice through the Prism of Information Politics and Resource Injustice: A Case Study from Hyderabad's Urban Frontier
}

\author{
Loraine Kennedy \\ CNRS-CEIAS, EHESS, Paris
}

Debdatta Chakraborty

Indian School of Business,

Hyderabad

\author{
Ashima Sood \\ Indian School of Business, \\ Hyderabad
}

\author{
Ram Mohan Chitta \\ Indian School of Business, \\ Hyderabad
}

\begin{abstract}
How does data visibility affect vulnerable communities that face uncertainty over occupational rights? Or in other words, can data justice be realized in settings of acute resource injustice? These are the overarching questions that our case study interrogates by opening up the black box of the community in the volatile and fast-transforming context of occupation rights on the peri-urban frontier. We examine the unfolding of data and information processes through the lens of enumeration and community mapping exercises conducted in a low-income neighbourhood or basti located in the fast-transforming periurban fringe of Hyderabad, India. We argue that the realization of data justice is mediated by 'information politics', i.e., the ways in which informational resources, as well as the risks and rewards associated with them, are distributed across individual actors and identity groups within the community. In so doing, our case study underlines the importance of a structural understanding of data justice and also suggests directions for embedding justice in data processes.
\end{abstract}




\section{A. Introduction}

How does data visibility affect vulnerable communities in cities of the global South? Does the increasing prevalence of digital technologies help realize data justice in settings of resource injustice? Or does it thwart it? While recent scholarship has examined data processes in low-income communities in the global South (Heeks \& Shekhar 2019), this literature has often focused on issues of justice surrounding data processes in the relationship between the community and external actors. Our aim here is to open up the black box of the community to understand information flows within it, in order to understand attitudes about, and receptivity to, data collection exercises.

The location of our study on the volatile peri-urban frontier of Hyderabad, in an area with little presence or activity of non-governmental organizations (NGOs) or community-based organizations ( $\mathrm{CBOs}$ ), allows a reckoning with the role of 'leaders' in mediating these information flows. Thus, we take as our variable of interest not simply data, which is in some forms inaccessible to the innumerate and the illiterate, but the larger landscape of information. The assumption is that our empirically grounded approach will generate insights into a range of questions at the heart of research on data justice in relation to access, receptivity and visibility.

We focus on two adjacent but discrete communities: a basti (slum) we call 'Gachi Basti' and a recently constructed 'transit' housing complex, designated here as the Provisional Housing Complex (PHC). ${ }^{1}$ Together they accommodate approximately 1,800 residents, although lack of basic data about these communities, including population, motivated our decision to undertake an enumeration survey (see below). Both families from the basti and current residents of the $\mathrm{PHC}$ have faced housing evictions in the last year. The trauma of these evictions, experienced by the evicted families but felt across the settlement, therefore provide the most immediate prism through which we engage with the questions of data and information justice. Our conceptual framework draws closely from the specificity of this setting, and we subscribe to Heeks and Renken's (2018) position that a structural approach offers an appropriate foundation for understanding data justice in a development context.

In particular, our study demonstrates the need to embed the data justice framework within a broader understanding of the politics of information and resource access. From the perspective of distributive or rights-based justice, we focus on the right of the marginalized communities to continue to reside in their self-built settlement and their right to basic amenities provided by the state. In this way, our conceptualization of distributive justice echoes the notion of a right to the city (Lefebvre 1996, Harvey 2003, Zérah et al 2011).

Millions of India's urban residents live in informal/illegal settlements. Although these areas cover a wide range of legal and material situations, they are invariably under-serviced areas

\footnotetext{
${ }^{1}$ The name of the basti and surrounding place names have been anonymized in light of the precarious circumstances of the basti dwellers.
} 
and home to the most socially and economically underprivileged urban residents. ${ }^{2}$ These citizens are increasingly integrated, voluntarily and involuntarily, into large-scale digitization exercises and databases. In some cases, such as India's unique identification system Aadhaar, which is based on an individual's biometric and demographic data, the ostensible aim is to improve access to public services and welfare schemes (Drèze et al 2017, Krishna 2019). Likewise, their exposure to video surveillance is justified in terms of greater safety and security (Rathi \& Tandon 2019).

In other cases, for which there is no solid body of evidence yet, these settlements, often in strategically located areas of the city with rising property values, become coveted objects of spatial mapping on the part of government planners, private property developers and land mafias. Our study is a first attempt to assess how local communities perceive their engagement in these different types of exercises in terms of risks and benefits. We show how knowledge/data about a community's physical occupation of space articulates with justice and rights in a local context. We argue that the residents' lack of occupation rights in conjunction with their lack of reliable information greatly intensifies their sense of insecurity and powerlessness. As Johnson (2014) and others have noted, land records digitization, upon which officially recognized land rights are based, is accompanied by significant hazards for people without secure tenure.

The context for this analysis is the western Hyderabad landscape also known as Cyberabad, a fast-transforming economic frontier for digital technologies. Expected to reach 10 million residents in the next decade, Hyderabad is one of India's IT services boomtowns. The city's development into an IT services powerhouse has been led by state government initiatives since the 1990s when the Chief Minister Chandrababu Naidu promoted the iconic HITEC City $^{3}$ enclave on the western periphery of the city to house IT and financial services majors. In the ensuing growth push, large tracts of land have been assigned to multinational and national IT-enabled services companies for campuses and Special Economic Zones. Existing farming and pastoral communities have found themselves pushed to the margins of these 'world-class landscapes' as older livelihoods and ways of living have been rendered unviable. At the same time, newer populations of migrants from neighbouring states have arrived to participate both in high skill professional jobs and in low skill services activities such as construction work, housekeeping, driving and domestic help to service the IT economy.

Against this backdrop, the questions raised by our case study about the relationship of new digital and data technologies to issues of distributive justice assume special piquancy. Our primary conceptual frame is one of 'information politics', i.e., the way information is used to wield power and to perpetuate information inequalities.

Our case study offers a grounded empirical examination of these questions through the lens of community mapping exercises in low-income communities located at the fringes of the information technology-led economy of western Hyderabad. Our major comparison is

\footnotetext{
${ }^{2}$ According to 2011 Census of India and National Sample Survey 69th Round, 2012, 65.49 million slum inhabitants live in 13.92 million households. The slum population is $5.4 \%$ of the country's total population and $17.4 \%$ of the total urban population (MHUPC 2015).

${ }^{3}$ Acronym for Hyderabad Information Technology and Engineering Consultancy City.
} 
between an enumeration exercise conducted by our research team and a community survey conducted by the local anganwadi or government-supported natal and childcare facility for the Integrated Child Development Services (ICDS). The first exercise, carried out by our team, consists of a household enumeration of the basti, including geospatial coordinates of individual dwellings. This exercise ran into concerted hostility from some basti leaders, making it difficult to complete the enumeration. Although incomplete, it nonetheless offered considerable insight into the informational landscape of the basti. This contrasts with the second, more formalized data generation exercise carried out by the ICDS, which was digitized for the first time this year via a smartphone app that included geotagging. Although the ICDS surveyors faced relatively little resistance in previous rounds, this year's exercise did elicit some resistance, indicating the larger sentiment of mistrust around digital technologies. Residents complained that both forms of data collection could expose them to eviction.

Among the key questions we seek to answer: What are the main structural and contingent factors that shape information politics in local communities? How are the broader information landscapes related to attitudes/perceptions about digitalization and about the risks and benefits of data collection exercises in particular? Our analysis has a two-fold scalar focus: first, the locality of Gachi Basti and the PHC as social units, with their internal divisions (based on political factions, class, gender, status as migrants or non-migrants). Second, we take into account the basti's relationship to the outside, whether as marginalized 'clients' in larger patronage networks, as low-income residents in an increasingly upscale area, or as citizens vis-à-vis state agencies.

Our findings suggest an arena of stark informational disparities between these vulnerable, indigent populations and the increasingly sophisticated digital data apparatuses used to encode them. Although the availability of digital audio-video technologies through cheap mobile networks among basti residents is rendering traditional hierarchies somewhat more volatile, it has not in any meaningful way disrupted the regulation of information flows by socially, economically and politically powerful actors. As we argue, the democratizing potential of emerging digital technologies is severely constrained by structural inequities across gender, caste, class, political and even linguistic lines. Therefore, data processes must take explicit cognizance of these disparities and fragmentation to ensure that data justice is realized. Our case study thus offers a cautionary note about 'naïve' data collection exercises that fail to recognize the internal structural differentiation of vulnerable communities. We argue for an explicit mapping of the information flows and associated information politics that characterize such settings.

In the next section, we outline the conceptual framework we employ to understand these findings. The following section gives an account of the methods employed during data collection and comments on the research design developed for this study. In the section on findings, we present the observations from the various methods of data collection, focusing on three key themes - the effects of information politics in datafication, receptivity to upstream datafication processes, and the use of technology in everyday lives. The fifth section ties together the evidence collected and concludes by highlighting the implications for future research on data justice themes in cities of the global South. 


\section{B. Background}

While the emerging literature on data justice has largely relied on theories developed or conceived in the global North (Taylor 2017, Heeks \& Renken 2018), a promising new strand of work evaluates how issues of data justice play out in the cities of the global South. Work in this vein has introduced a valuable element of empirical engagement with themes that animate wider urban governance modalities at the interface of the formal and the informal in these settings (Donovan 2012, Heeks \& Shekhar 2019). Our case study, although located in a larger literature on datafication in informal settlements in cities of the global South, nonetheless departs from it in several respects. Key to the contribution of our study is its setting on the peri-urban frontier of one of India's premier IT hubs. First, it allows us an opportunity to assess the existence of channels for the diffusion of digital technologies across physically adjacent spaces. Second, it represents an uncharted terrain as far as NGOs and CBOs are concerned. For the vast majority of existing studies (Lundine et al 2012, Shekhar 2012, Panek \& Sobotova 2015, Hagen 2017 and others cited in Heeks \& Shekhar 2019 as well as in Patel \& Baptist 2012), reliance on a variety of such intermediaries and/or leaders tends to obscure internal differentiation within the 'community'.

Our case study thus opens up the black box of the community to reveal the internal fissures and fragmentation that mark the information landscape in settings without active civil society intervention, the default in most peri-urban sites. Given the unique features of our case, our approach has been inductive. The aim has not been primarily to test hypotheses suggested by the data justice literature but to understand and derive a picture of information flows within and beyond the communities under study. As indicated, our variable of interest is not simply data, but the larger landscape of information.

Figure 1 maps out the internal divisions that mark our sites and the potential interfaces with the outside world. These interfaces also represent possible opportunities for information outflow.

Figure 1: Internal Divisions and Potential Information Flows outside the Community

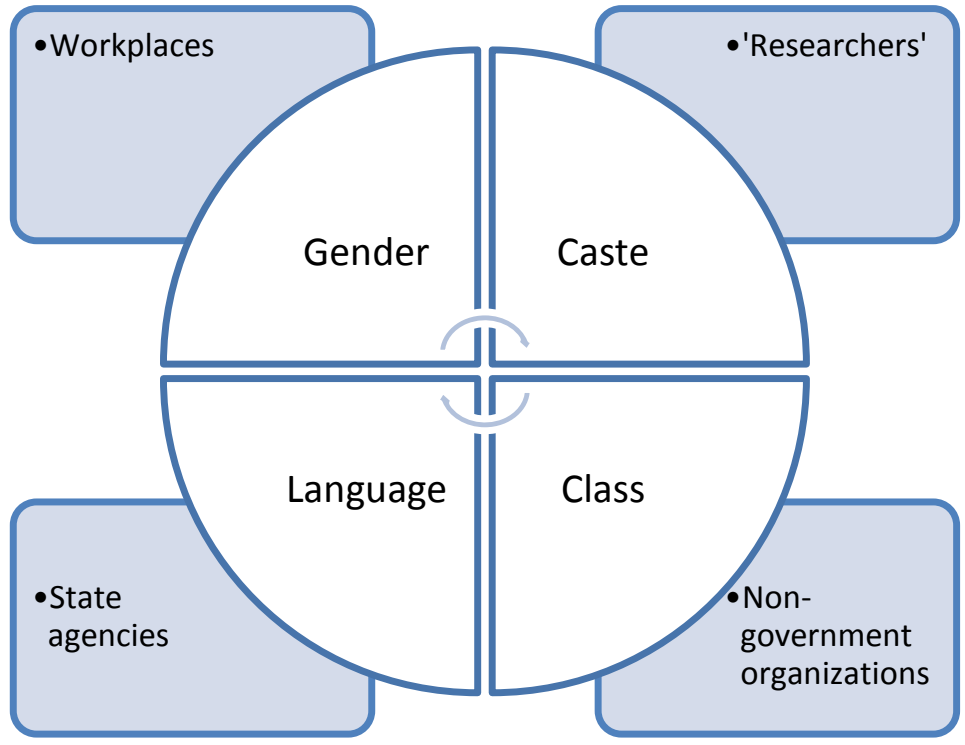


Our setting thus leads us to adopt a critical approach, recognizing that structural conditions, including institutions that embody those conditions, shape both the distribution of data resources and the patterns of benefits that derive from them (Johnson 2014, Heeks 2017, Heeks \& Renken 2018). This approach involves examining how social, political and institutional structures condition access to information as well as services and/or resources. Our focus on how conflicting interests underpin the generation and sharing of data/information and on how issues of access to data/information intersect with larger power relationships underlines the political economy of information in this setting.

Nonetheless, our analysis allows for individual agency within the broader structural approach. Our case will contribute to a reflection on how to expand on a structural framework to encompass the empirical realities of the field. We draw on Heeks and Renken (2018) to examine various dimensions of data justice. Our conceptual frame for understanding the role of structural factors is the idea of information politics.

Although instrumental concerns have been shown to shape data processes in this type of setting (Heeks \& Renken 2018), our analysis suggests the need to qualify this understanding in specific contexts. For example, from the perspective of the residents, "downstream" 4 processes of execution would appear to matter significantly. As our interviewees repeatedly told us, they believe that previous attempts by government agencies to collect data led to disastrous consequences in terms of demolition and eviction. Thus, our findings would suggest that an instrumental perspective should apply both to risks and rewards that accrue from information sharing.

However, in fact, the ostensible salience of instrumental concerns is mediated by issues of distributive justice and undercut by the real structural imbalances in access to data and information across the state agencies and the residents. This is because the distribution of rewards from information exchange depends critically on the individual's location within the landscape of information politics. As many of our Dalit ${ }^{5}$ and female respondents reminded us, they were the ones to bear the brunt of the risks of sharing information with outsiders. In contrast, basti leaders were often able to capitalize their strategic position within community information flows to consolidate the rewards they accrued for transmitting information to elected representatives at various levels. Thus, structural data injustices both configured and were reconfigured by the broader information politics of this setting.

\footnotetext{
4 "Downstream" here refers to later activities in the "information value chain" (Heeks \& Shekhar 2019): the use of processed data in the form of information, for decisions and actions about or by basti residents. "Upstream" refers to earlier activities: the gathering, processing and visualization of data about low-income settlements. ${ }^{5}$ Dalit ('oppressed') is the term used to designate various groups who have suffered institutionalized discrimination because of their position at the bottom of the ritual hierarchy under Brahmanical Hinduism.
} 


\section{B1. Occupancy as a structural factor}

The vast majority of the basti inhabitants have no legal rights but only a tenuous form of occupancy rights over the place they live. ${ }^{6}$ Yet their continuous occupation over several decades has given them a sense of entitlement to this place; their settlement long preceded the arrival of Cyberabad and the high-rise gated communities.

In particular, the issue of illegality is central to an understanding of this case and its theoretical significance. The lack of a legally sanctioned presence in this place leaves its residents at the mercy of distant bureaucrats, elected officials and members of the community with ambitions. At the same time that residents are distrustful of becoming part of a database, they are desperate to establish their right to stay. To do so, they call upon a collective shared history, which is often implicit, community-based knowledge to corroborate their claims and position themselves in relation to more recent arrivals. Likewise, they make paper claims (formal, bureaucratic knowledge) such as electricity or water bills as proof of residency (see also Ranganathan 2013). Several respondents whose houses were demolished believe those latter forms of proof should have provided protection. Many told us, "we built our homes and nobody said anything". ${ }^{7}$ In other words, a lack of punitive action on the part of the state was interpreted as consent. Far from irrational, this is emblematic of the way the urban poor navigate in their 'negotiated', never fully secured, right to the city (Benjamin \& Raman 2001, Zérah et al 2011).

This case underscores the necessity to recognize how seemingly antagonistic regimes coexist simultaneously: for instance, one based on private property rights and one based on occupation rights. Occupation rights are de facto recognized in India in specific settings at specific points in time (Benjamin 2008), although they must be constantly renegotiated. A key question is whether data-intensive development practices can co-exist with the informal 'management' of populations by the state (Chatterjee 2004, Roy 2009), based on the implicit recognition of the rights of vulnerable communities to the commons (property or resources). Thus, our notion of information politics resonates with structural approaches to data justice.

\section{B2. A frontier setting?}

Our study can contribute to wider debates on data/information justice. In many respects, it is an extreme case, focused on people with multiple vulnerabilities: social (illiterate, low caste), legal (without legal tenure, squatters) and spatial (located at the urban frontier, in the interstices of rapidly transforming high-value land). Yet although extreme, it is not marginal in the sense that it is emblematic of many situations in India, involving millions of citizens. Two important features of our setting particularly deserve notice.

\footnotetext{
${ }^{6}$ The Basti Development Committee president claimed that the basti land was allotted to them by a previous chief minister but he had no knowledge of any document officially recognizing the same. Interview, 25 February 2019.

${ }^{7}$ Recorded during the focus group discussion with evicted residents at the PHC on 24 February 2019.
} 
First, unlike several of the case studies discussed in Heeks and Shekhar (2019), Gachi Basti is a frontier setting which has seen little intervention by community-based organizations or civil society groups. As a result, residents have little experience with instrumentally 'fair' data processes mediated by such groups.

Second and equally important, the information landscape of the basti is highly fractured on lines of caste, ethnicity, language, gender. The basti leaders occupy important nodes of power, largely by proxy, by virtue of their links to politicians. These include, but are not limited to, the elected corporator of Greater Hyderabad municipality and the local Member of Legislative Assembly (MLA). As we document below, this differential access to information by different groups within the basti and the tight regulation of information to and from the basti by the leaders have serious consequences for shaping the information inhabitants have about their entitlements.

In other words, the achievement of procedural, instrumental or distributive data justice ${ }^{8}$ is fundamentally determined not only by the larger structures of power in terms of statecitizen relationships, which have received attention in the existing literature (Heeks \& Renken 2018), but also by the power asymmetries at the micro-level of the basti. The slum's dominant social structures affect data processes, as well as their outcomes. This is the essence of our focus on information politics. As we document in our findings below, the choices available to individuals and their capability to exercise control over their lives are enabled and constrained by broader social structures.

\section{Methods}

As indicated above, our field site comprises Gachi Basti, a locality classified as a slum as per municipal surveys in Greater Hyderabad, and its neighbouring PHC blocks. The background and rationale for our choice of the site come from the housing vulnerability that shapes the experience of communities such as these. In August 2018, authorities demolished 56 houses in Gachi Basti in an early morning raid, leaving the residents deeply shaken and rendering numerous families homeless. These families were allotted housing in the PHC at the other end of the basti. Shortly before that, in April 2018, some 200 families were also shifted to the PHC from another demolition site, nearly 10 kilometres away. Those families had lost their houses to a slum-wide demolition drive that occurred after a fire accident. Before developing our research methods in more detail, a brief description of the field site provides important context.

Gradually built-up through self-construction starting in the 1980s, the core community of Gachi Basti belongs to a so-called "backward" caste and members of this group worked until recently as stone crushers in the nearby quarries. They migrated over time from northern Telangana (the Indian state of which Hyderabad is the capital) and the border area with the

\footnotetext{
${ }^{8}$ These are three dimensions of data justice (alongside rights-based and structural): procedural refers to "fairness in the way in which data is handled"; instrumental to "fairness in the results of data being used"; and distributive to "the (in)equality of data-related outcomes" (Heeks \& Shekhar 2019:995). For further details, readers are referred to Heeks and Shekhar (2019).
} 
neighbouring state of Karnataka. Telugu is the native language spoken by the majority of the population. Some of the families who once spoke Kannada (native to Karnataka), adopted Telugu as their first spoken language. The area started rapidly transforming from the late 2000s. The privately-operated quarries were shut down in 2009 and the land became increasingly occupied by the rapidly expanding IT cluster, which is characterized by largescale housing compounds and office complexes that accommodate globally-connected firms employing highly educated professionals. Some people from the local communities found jobs in the cluster in "housekeeping" (cleaning and maintenance), security services, etc., although many lack the minimum qualifications and skills required.

Since a large proportion of the residents of Gachi Basti belongs to a single caste, there is a sense of connection among people, even when they are not directly related. However, our investigation also indicates deep internal divisions, although the nature of the fracture lines - political, ideological, class or ethnicity - is not entirely clear. Basti leaders, all men, are aligned to more powerful politicians or movements and individuals appear to be loosely affiliated to one or the other faction, although there is fluidity and overlap. In addition to the more established third-generation residents, our incomplete enumeration exercise revealed a significant number of non-Telugu-speaking migrants, from outside Telangana, renting accommodation in the basti. They are engaged in largely unskilled service activities such as construction work, housekeeping, driving and domestic help.

The approach to empirical research adopted for this study was case study strategy, based on mixed qualitative and quantitative research methods. These included observation during frequent visits to the locality, interviews with key informants, and focus group discussions with residents. Within the community, our informants included basti leaders, a leader of a women's self-help group as well as government functionaries such as anganwadi workers, water board employees or education inspectors. Informants outside the community included elected officials and municipal officers. In addition to questions on information flows, we investigated the impacts of new technologies, smartphones and various datafication processes, with the aim to assess how increased access to digital data is shaping social dynamics in the slum, such as access to employment, information about government schemes and knowledge about rights (to public services and property). Although not initially a focus of our research design, the PHC on the edge of the basti took on significance in light of the fact that evicted residents of Gachi Basti were resettled there.

\section{C1. Enumeration exercise}

We initially planned an enumeration exercise in order to allow us to develop a stratified sample survey of residents who could be further interviewed individually. In our interviews with leaders of the basti and the focus group session with the residents at the PHC blocks, we discussed our upcoming fieldwork at the basti. The leaders and other residents were open to sharing information about Gachi Basti and offered to introduce us to other residents. ${ }^{9}$

\footnotetext{
${ }^{9}$ Interviews, 22 February 2019.
} 
After obtaining consent from residents, we used smartphones to collect data about their family size and house, geo-tagging each residence (Table 1 ). Despite giving consent, it soon became clear that many residents had doubts about the aims of our study.

Members of our team were asked about the intentions and end-use of our data collection. The digital mapping through GPS, in particular, was seen as risky. As we were employing, in parallel, a numbering system on printed Google Maps, residents expressed worry about the need for a geographical survey. As the news/misinformation spread in the basti about our enumeration exercise, households refused to share data unless the basti leaders intervened. Hostility to the enumeration process was ostensibly demonstrated most vocally and persistently from one basti leader, who instructed residents not to cooperate with us. This man insisted that we stop visiting the basti and threatened our collaborators with physical harm if we continued. ${ }^{10}$ Although several of the leaders were individually open to our presence and survey, their multiple political affiliations had fragmented into discrete spheres of influence, making it difficult to bring them to common ground.

As we sought to understand the apprehensions of the residents, we learned that a similar exercise had been linked in the residents' minds with the eviction drive conducted by the Mandal Revenue Office (MRO). ${ }^{11}$ As one resident put it,

Even before the eviction, people like you came in to the basti and took our information posing as government servants and bank officers. Then the result of it was the eviction as you see it. Now we feel afraid to share information with anyone. ${ }^{12}$

As this suggests, and as we elaborate below, what people believe happened in previous data collection processes, and its link to eviction, colours their views on subsequent exercises. The findings from the partially completed enumeration are presented in Table $1 .{ }^{13}$

Table 1: Enumeration Exercise Results

\begin{tabular}{|l|l|l|l|}
\hline $\begin{array}{l}\text { No. of households } \\
\text { (also no. of } \\
\text { responses) }\end{array}$ & $\begin{array}{l}\text { No. of families } \\
\text { renting out a } \\
\text { house/a room (out } \\
\text { of 125 responses) }\end{array}$ & $\begin{array}{l}\text { Reported no. of } \\
\text { residents in the } \\
\text { surveyed } \\
\text { households }\end{array}$ & $\begin{array}{l}\text { No. of households } \\
\text { with at least one } \\
\text { mobile phone }\end{array}$ \\
\hline 181 & 31 & 770 & 171 \\
\hline
\end{tabular}

Source: Author's calculation based on primary data.

Note: We recorded a unit of household based on the Census of India definition, i.e., a group of individuals living together and sharing a common kitchen. In the second column, we were able to collect only 125 responses; in the absence of legal rights over the land on which they have constructed their houses, many families were not willing to reveal to us whether they lease out a part of their house to others.

It is worth noting that the survey was conducted in almost half of Gachi Basti. Among the households surveyed, $74 \%$ (134 households) were one-room structures. We observed that as the survey approached the part of the basti where the eviction had taken place,

\footnotetext{
10 Interaction, 4 March 2019.

${ }^{11}$ A local government office responsible for a variety of state functions within a local area.

12 Interview with a daily wage worker staying at Gachi Basti on 23 February 2019.

${ }^{13}$ In our enumeration exercise, several respondents asked what tangible benefits they would receive if they answered our survey. See further discussion in the section on Findings.
} 
resistance from residents to our enumeration became more pronounced. People brought up the recent eviction drive as a lesson to avoid sharing information with 'outsiders'.

In addition, we also spoke to the families who were recently evicted from the basti and placed in the PHC in two focus group discussions. This access has given us important insights into the politics of information, and data justice more broadly. It is interesting to note that the respondents were more open to sharing opinions and information in open-ended interviews. One woman even commented,

... people like you [researchers] should come to the basti and observe our living conditions. But today we do not know who represents what or who to believe; we are scared because we have been betrayed. ${ }^{14}$

Our methodology and the main sources of our primary data are summarized in Table 2.

Table 2: Methods and Coverage

\begin{tabular}{|l|l|l|}
\hline Method & Site & Number / size \\
\hline Interviews & $\begin{array}{l}\text { Residents and } \\
\text { representatives in PHC } \\
\text { and Gachi Basti }\end{array}$ & 23 in-depth interviews \\
\hline Media reports & $\begin{array}{l}\text { Reports on eviction in } \\
\text { print and television news } \\
\text { (TV news uploaded to } \\
\text { YouTube) }\end{array}$ & $\begin{array}{l}\text { 5 print news reports (in English) } \\
\text { and 12 TV news coverage } \\
\text { reports (on YouTube) }\end{array}$ \\
\hline Focus group discussions & Gachi Basti and PHC & $\begin{array}{l}\text { Two; one each with evicted } \\
\text { family members of Gachi Basti } \\
\text { (five participants) and the } \\
\text { evicted residents of the basti } \\
\text { where the fire occurred (six } \\
\text { participants) }\end{array}$ \\
\hline Household enumeration & $\begin{array}{l}\text { Gachi Basti } \\
\text { Basti community meeting } \\
\text { for caste association/ } \\
\text { HMWS\&SB office, } \\
\text { Anganwadi centre, basti } \\
\text { house construction site }\end{array}$ & $\begin{array}{l}\text { 3 situations } \\
\text { Telangana Housing Board, } \\
\text { HMWS\&SB, MRO, ICDS } \\
\text { (Anganwadi), Municipal } \\
\text { Corporators office, } \\
\text { Mandal Education Office } \\
\text { and GHMC office }\end{array}$ \\
\hline $\begin{array}{l}\text { Administrative data } \\
\text { collection }\end{array}$ & $\begin{array}{l}\text { Multiple visits to each: data } \\
\text { collection (public land records), } \\
\text { interviews with key informants }\end{array}$ \\
\hline
\end{tabular}

Source: Compiled by the authors.

Notes: HMWS\&SB is the Hyderabad Municipal Water Supply and Sewerage Board, ICDS stands for Integrated Child Development Services, GHMC stands for Greater Hyderabad Municipal Corporation.

${ }^{14}$ Focus group discussion with evicted residents at the PHC on 24 February 2019. 


\section{C2. Comparing with the ICDS survey}

The anganwadi survey conducted by the state government's ICDS was used as a comparative benchmark for our team's enumeration. In its prior iterations, the anganwadi survey was conducted on paper to calculate the population and family sizes in the basti. The survey recorded data based on the Aadhaar identity number of residents to provide prenatal and post-natal services to pregnant women and their children (see, for example, Table 3 ). The data was recorded on registers to keep track of the population in order to deliver adequate services.

Table 3: Consolidated Data from the 2018 Anganwadi Survey

\begin{tabular}{|l|l|l|l|l|l|l|l|}
\hline $\begin{array}{l}\text { Number } \\
\text { of Males } \\
\text { (Above }\end{array}$ & $\begin{array}{l}\text { Number } \\
\text { of } \\
\text { Females 6) }\end{array}$ & $\begin{array}{l}\text { Number of } \\
\text { (Above } \\
\text { Age 6) }\end{array}$ & $\begin{array}{l}\text { Number of } \\
\text { Women }\end{array}$ & $\begin{array}{l}\text { Mothers } \\
\text { with } \\
\text { (Age } \\
\text { Newborn } \\
\text { Children }\end{array}$ & $\begin{array}{l}\text { Girls } \\
\text { (Age } \\
0-6)\end{array}$ & $\begin{array}{l}\text { Total } \\
\text { Number } \\
\text { of } \\
\text { Families }\end{array}$ & $\begin{array}{l}\text { Total } \\
\text { Population }\end{array}$ \\
\hline 772 & 734 & 8 & 11 & 10 & 15 & 253 & 1541 \\
\hline
\end{tabular}

Source: Based on data collected by the State Government under the annual ICDS survey conducted in 2018. Note: Unlike the household definition used in our enumeration exercise (see Note, Table 1), the anganwadi data considers families related to each other, and living next to each other, as a single household. The anganwadi survey encountered technical problems in recording data in the PHC, hence the above data does not cover most residents in the PHC.

The anganwadi digitized the survey for 2019 using an app developed by the ICDS. The digitized survey records data about the family members along with the geographical coordinates (geotagging) of each household. We interviewed the anganwadi surveyors while the digitized survey was ongoing, to understand the reception of the basti residents to the new survey method. The surveyors reported that some residents who had recently moved into the basti expressed fear over the use of digital technology and hence, refused to share their data. These specific families were afraid that digitally recording their presence in the basti would make them more vulnerable to eviction. The surveyors were reminded of the eviction that took place last year and were told by those families that recording such data posed a threat to their homes. ${ }^{15}$

15 Interview with the surveyor, 4 June 2019. 


\section{Findings}

Our case study analysis yielded three main findings corresponding to our research questions outlined at the outset. First, issues of data justice are embedded in informational politics i.e., the ways in which informational resources, as well as the risks and rewards associated with them, are distributed across individual actors and identity groups. This information landscape is shaped by structural factors. Secondly, instrumental concerns shape data processes in this setting to a degree, and in some contexts, downstream processes appear to matter. However, the internal disparities in the community mean that structural factors dominate more than instrumental concerns. Third, residents in the basti have differential access, capabilities and attitudes to digital technology. These findings are further developed below.

\section{D1. Datafication processes are influenced by wider structures of power, which mediate information politics}

We argue that issues of data justice are embedded in informational politics, i.e., the ways in which informational resources, as well as the risks and rewards associated with them, are distributed across individual actors and identity groups. Widespread illiteracy and innumeracy are underlying contextual factors that inhibit growing datafication from having a 'liberating' effect in the form of access to independent sources of information. The social hierarchy of the community is also a major impediment to the free flow of information, and the community's internal power structure, therefore, becomes crucial to the analysis.

As Figure 2 shows, basti leaders centralize information flows. This convergence is facilitated by the fact that the slum is fragmented in terms of caste, language, gender, ethnicity and political affiliations. This also leads to informational disparities among various groups with implications for their participation in political processes. In addition, the gatekeepers of the slum exercise tight control over the information value chain, by controlling both the inflow and outflow of information (see Figure 3). 
Figure 2: Information Flows within the Community

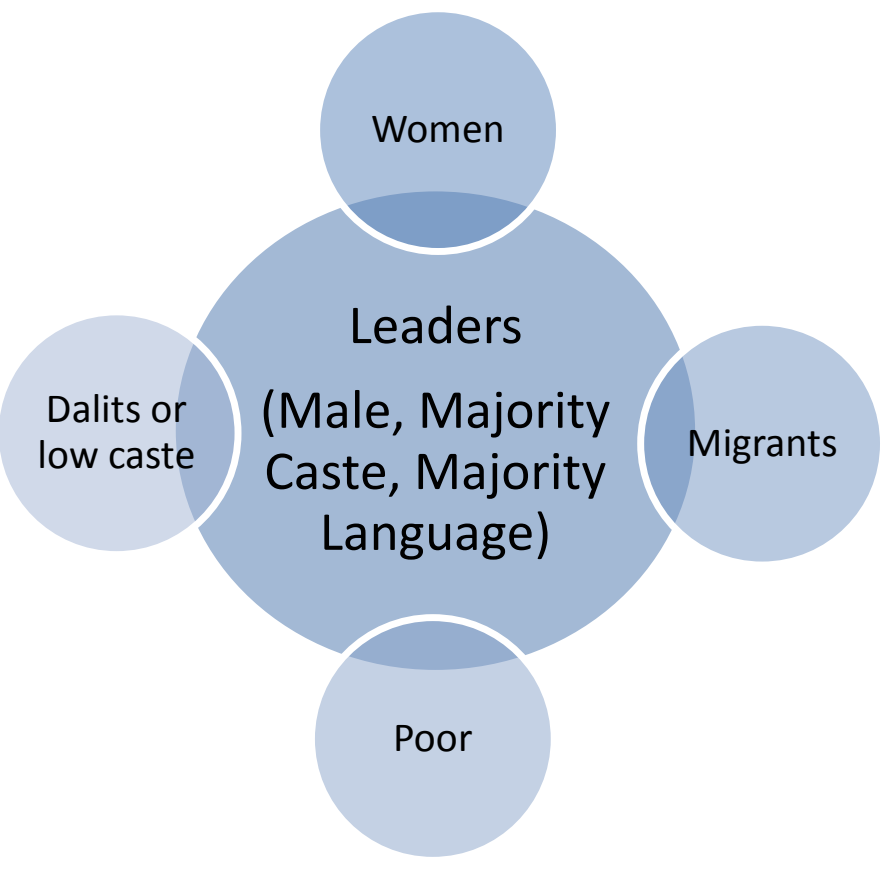

Figure 3: Upstream and Downstream Activities Work within the Information Politics of the Community

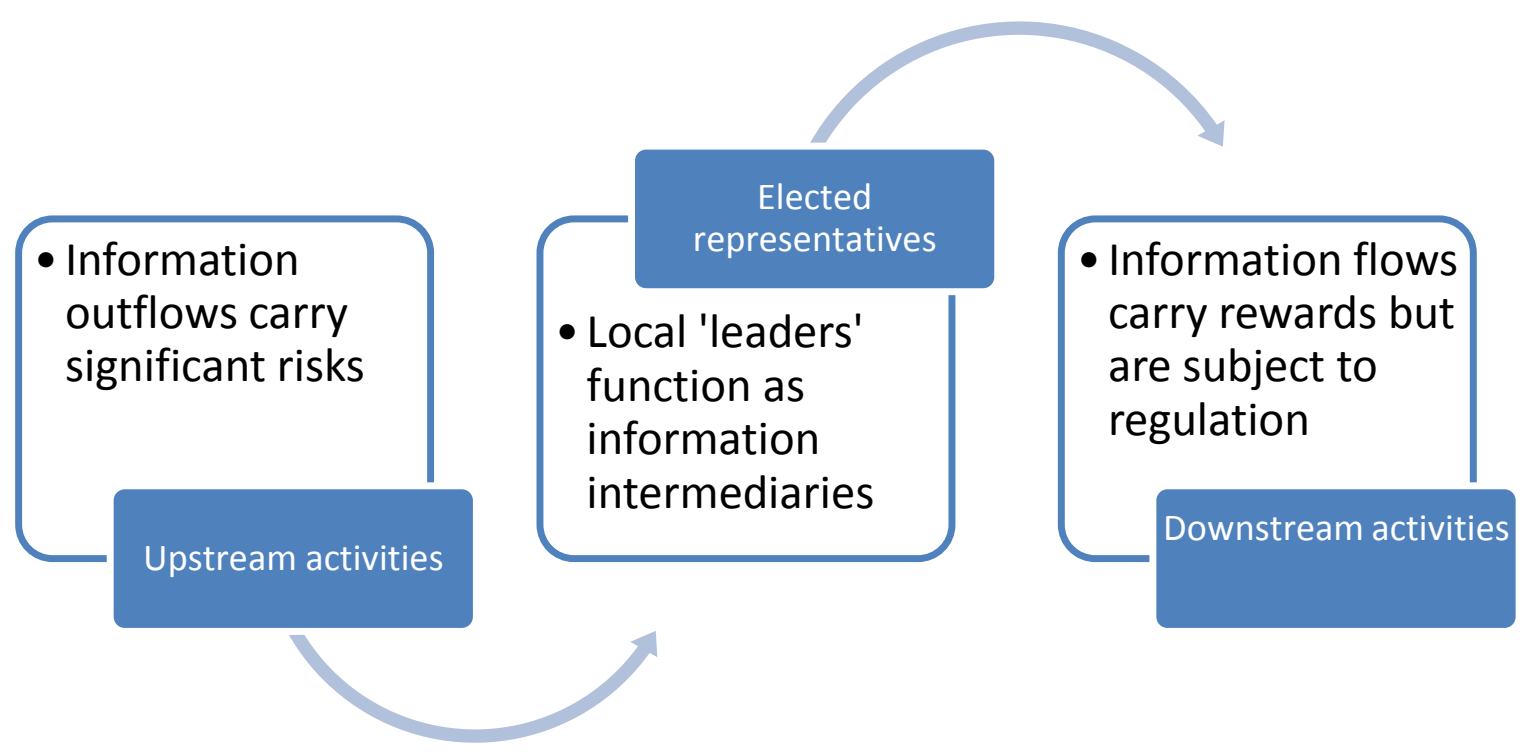


In terms of social structure, it is significant that neither of these settings (Gachi Basti or PHC) has active formal CBOs or non-partisan NGOs. While the resettled families in the PHC are supported by a church headed by a local pastor, the Hindu nationalist organization, the Rashtriya Swayamsevak Sangh (RSS), has an active presence in Gachi Basti. The overtly political agenda of the RSS, articulated through the electoral politics of the ascendant Bharatiya Janata Party (BJP), lends a strong 'political society' orientation to collective action in the community (Chatterjee 2004).

Party politics is a significant mode through which community grievances and demands find expression. The major political parties install local 'leaders' who play a key role in transmitting information from elected party officials higher up in the chain and in turn communicating community issues to elected representatives. For example, immediately following the demolition at the basti, local BJP cadres organized vehicles to bring people to the administrative office and led the protest. The protesters were taken into police custody and court cases were initiated against them. Several of the women who had been arrested admitted to being completely unaware of the grounds of their conviction or the litigation process.

In our focus group discussions, respondents reported that only leaders remained in contact with municipal officials and elected representatives. This forced community reliance on the leaders for all issues pertaining the basti, including housing and development work. One of the women who lost her house in the eviction drive and got arrested in a subsequent clash with the police remarked about the leaders:

[T] hey are all hungry for power. I went to their doors over ten times after my release to ask about our home, but none of them helped me. (...). These leaders even mediate our talks with the MLA and do not allow us to question him directly. Our family has been living here for three generations now, but we still do not have a place in our own basti. ${ }^{16}$

The evictees from the basti at the PHC said that when they tried to meet the elected representatives on their own, they were turned away and told to "behave themselves" and communicate through their leaders. ${ }^{17}$

The people in the PHC have little idea about what the government has planned for their future accommodation; they were promised individual apartments by their political representatives, but there has been little further news about that. Almost without exception, respondents lacked certainty about the title deeds or patta on the land they occupied. Some claimed they possessed patta, but that the municipality is holding their legal documents as a form of collateral. These claims could not be cross-checked.

If information is power, the political profoundly shapes information flows in these settings. Thus, the politics of information become salient and even central both to spatial resource and data justice agendas. However, collective action is made difficult by the sheer fragmentation of the terrain. Thus, although they live adjacent to each other and share

\footnotetext{
${ }^{16}$ Focus group discussion with evicted residents at the PHC on 24 February 2019.

${ }^{17}$ Focus group discussion with evicted residents at the PHC on 24 February 2019.
} 
common issues, the people belonging to the main caste group of Gachi Basti do not speak to the Dalit evictees from the fire who live in the PHC. Similarly, although they occupy the same physical space, language barriers divide the migrant renters from outside the state from local Telugu-speaking communities.

These constraints further reinforce the politics of information. Information transmission for vulnerable groups, in particular, women, the evicted, and Dalits, carries considerable risks. In both our field sites, our interactions with local community actors were often subject to approval and redirection by the 'leaders' and occasionally self-appointed gatekeepers who attempted to determine the topics of discussion.

To summarize, the internal structure of power in the slum is a crucial dimension of the analysis. We found that the slum was fragmented in terms of caste, language, gender, ethnicity and political affiliations. This leads to informational disparities among various groups along with implications for their participation in politicized informational processes (see Figure 4).

Figure 4: Information Intermediation in the Community

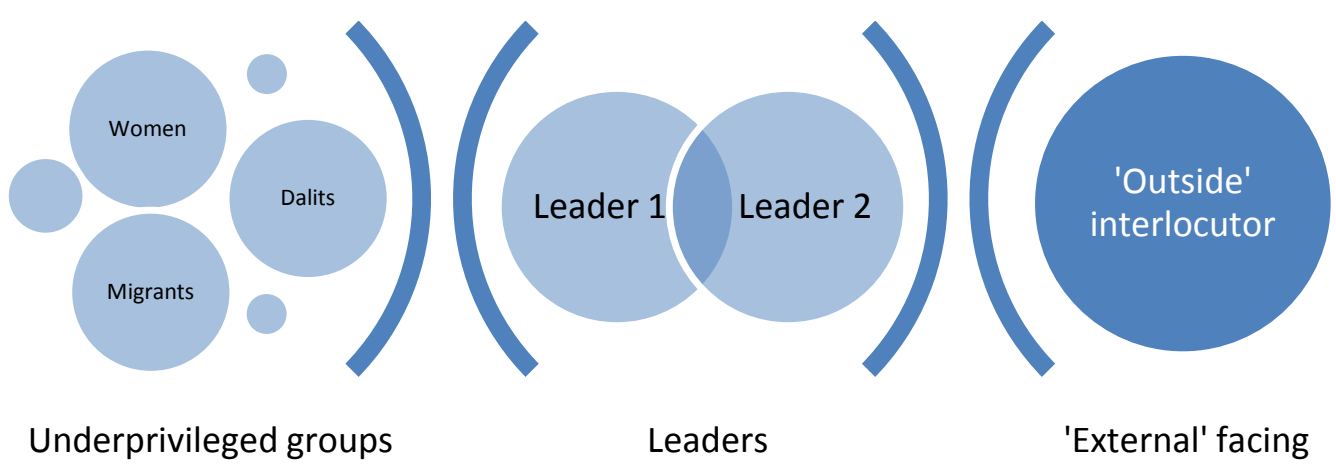

\section{D2. The assessment of downstream effects shapes receptivity to upstream activities, but only to a degree}

Our information politics framework pays careful attention to distributive issues of the risks and rewards of information flows. Instrumental concerns, i.e., the perspective of gaining benefits downstream, do appear to shape data processes in this setting. However, this needs to be qualified as expectations about outcomes can lead to cooperation or resistance depending on whether they are perceived positively (benefits) or negatively (risks). Previous experiences certainly condition whether residents will cooperate or resist attempts at data collection. If residents were reluctant or refused to participate in our enumeration exercise, it is probably because there were no tangible benefits they could anticipate.

Moreover, as we explained above, in the sheer informational miasma that characterized residents' understanding of the outcome of the data they had shared with government 
agencies, many were convinced it had led to their eviction. This explained heightened anxiety and resistance from them to further attempts at datafication, both our enumeration and the digitalized ICDS survey. However, not only is the receptivity to the ICDS survey hardening somewhat in the aftermath of the demolition, it is worth noting that there may be some grounds to the widespread perception that the pre-demolition survey was intended to support the eviction. There is considerable evidence available, both from our interviews with residents, as well as the spatial characteristics of the demolition site that the authorities had spatial information on the basti. ${ }^{18}$ We were not able to confirm this in our interviews with officials because of the politically sensitive nature of the eviction. Moreover, the responsible officers in the MRO that were directly involved with the demolition were transferred in the weeks following the incident and were hence not available. ${ }^{19}$ More importantly, the local Member of the Legislative Assembly, the most important elected representative at the state level explicitly linked the demolition to the spread of 'encroachment' on land designated for a housing scheme by the central government. ${ }^{20}$

In an interesting contrast, we observe there is greater openness to sharing information when residents perceive tangible benefits. The water board and the electricity board have information about the basti (names, house number, location, phone number), which the residents shared in order to receive services. ${ }^{21}$ The anganwadi survey generally met with little resistance due to the physical presence of the anganwadi centre in the basti for the past seven years, and the familiarity of the residents with the anganwadi facilitators (teacher, helper), unlike our own team of enumerators.

Corroborating findings from other studies (e.g. Heeks \& Shekhar 2019), we observed an ambivalence between the desire to remain invisible and the desire to be recognized as legitimate citizens, with occupancy rights. For instance, renting rooms to migrants is an important source of livelihood for the basti residents, which they want to hide from the authorities. Their current anxiety, exacerbated by the recent demolition and eviction, has made them wary and suspicious of data collection exercises.

\footnotetext{
${ }^{18}$ Using Google Maps, we could see that the polygon of the evicted site measures exactly the area that officials had claimed was encroached or illegally occupied prior to the eviction.

19 Interview at the Mandal Revenue Office, 26 February 2019.

20 This statement was recorded in interviews in the press after the eviction. We are not referencing these reports so as to not divulge the name of our field site.

${ }^{21}$ Information collected from the Water Board, Hyderabad, 31 March 2019.
} 


\section{D3. Digital audio-video technologies are increasingly available in the basti, but they have not disrupted the regulation of information flows by powerful actors}

Regarding the role of digital technology in the basti, our field investigations examined exposure to digitalization at various scales, starting with access to the internet. We collected data on the types of information people access through technology. We found that people in the basti have differential access, capabilities and attitudes to digital technology.

Out of the 181 households covered by our incomplete enumeration exercise, 171 or $94.5 \%$ owned at least one mobile phone. Of these 171, 67 households (37\%) owned one mobile phone each, while 72 households (40\%) owned two and $32(18 \%)$ of those surveyed possessed more than two mobile phones. ${ }^{22}$

The use of technology is deeply gendered. In most instances, the man of the household owned a mobile phone which was shared by his spouse. Several respondents (men and women) said that women are not educated enough to handle mobile phones, or that women do not need mobile phones because they would stay at home most of the time. ${ }^{23}$ The idea of women's safety was also invoked to discourage women from using digital technology. It was claimed that the use of smartphones by women and their presence on social media can attract unwarranted male attention in the form of stalking. ${ }^{24}$

Digital technology puts the inhabitants of the basti into big data systems like Aadhaar, Google Maps or open data sources like YouTube. YouTube videos played important roles in our interaction with the basti and PHC inhabitants. Videos of both the Gachi Basti eviction and the fire that brought evacuees from further afield to the PHC are available on YouTube. Several respondents showed us such videos of the demolition and the fire respectively to substantiate their claims. While talking to people outside the basti about their precarity, they use the videos as evidence to testify the claims they make.

We did not find evidence that digital technology is being used for accessing information pertaining to employment opportunities or government schemes. One exception was security personnel working for a global firm staying in the basti, who claimed to have a WhatsApp group with colleagues where they share work-related information. Migrant workers, residing in the basti, working in housekeeping or security services in the surrounding IT hub used mobile phones to keep in touch with their families, irrespective of

\footnotetext{
${ }^{22}$ We did not record data on smartphone (as opposed to basic mobile phone) possession because of concerns residents expressed before the beginning of the survey. As one respondent said, "I bought this [showing his smartphone] with my hard-earned money. You cannot question what I have." Recorded during our enumeration survey on 3 March 2019.

${ }^{23}$ Respondents expressed such opinions during interviews and focus group discussions at the PHC when questioned about their use of mobile phones.

${ }^{24}$ Interviews with the migrants residing in the basti and the focus group with the fire victim families in the PHC, 24 February 2019, 9 March 2019.
} 
gender. ${ }^{25}$ While smartphones seemed to be primarily used for entertainment purposes and local news, inhabitants of the PHC had a WhatsApp group.

Under such circumstances, does differential access to technology-enabled information create new divisions among the residents of the slum? Rather than subverting the existing power structures in the basti, e.g., by easing access to various types of information among the residents, digital technologies may, on the contrary, strengthen them. Basti leaders may use technology as a means of increasing their control over the inhabitants. An example is the RSS youth leader circulating images of our team through WhatsApp to the people in the slum so that they would not share any information with us. Similarly, we found that elected representatives and other politicians used digital means such as WhatsApp to exclusively communicate with the leaders, rather than the community at large. ${ }^{26}$

At the same time, being part of the Aadhaar digital database has become central to gain access to all kinds of government services like admission to a school, water supply, bank accounts, etc. It is symptomatic that some families in the PHC have pasted their Aadhaar cards on their doors. In response to our questions, we were told it is to establish proof of their identity so that no one can question their stay in the PHC. ${ }^{27}$ It is noteworthy that people working as domestic servants at the gated communities in the neighbourhood have to present their Aadhaar card each time they enter their workplace.

In summary, while making these communities more visible to state apparatuses, there is little evidence that digital technologies have empowered them in meaningful ways or subverted the internal power structures in the community.

\footnotetext{
${ }^{25}$ While most of the interviewed migrant women did not have smartphones, they did possess basic mobile phones that they would use to communicate with their distant families. Interviews conducted with migrants working in housekeeping, Gachi Basti, 10 March 2019.

${ }^{26}$ Interview with local corporator and staff, Khajaguda, 26 February 2019.

${ }^{27}$ Field visit, 24 February 2019.
} 


\section{E. Discussion and Conclusions}

Following from, but also nuancing Heeks and Renken (2018), our findings highlight the centrality of structural issues in shaping the relevance of other approaches to data justice. As Figure 5 shows, this is a key component of the information politics framework that we propose. The internal power dynamics as well as the relationship of the basti with the larger institutions of power - i.e., information politics - determine the data-information-decisionaction processes (who knows what and to what ends). It conditions the procedural, distributive, institutional and rights-based dimensions leading to information justice.

Figure 5: Information Politics - Instrumental, Distributive and Procedural Approaches to Data Justice are Mediated by Structural Dimensions

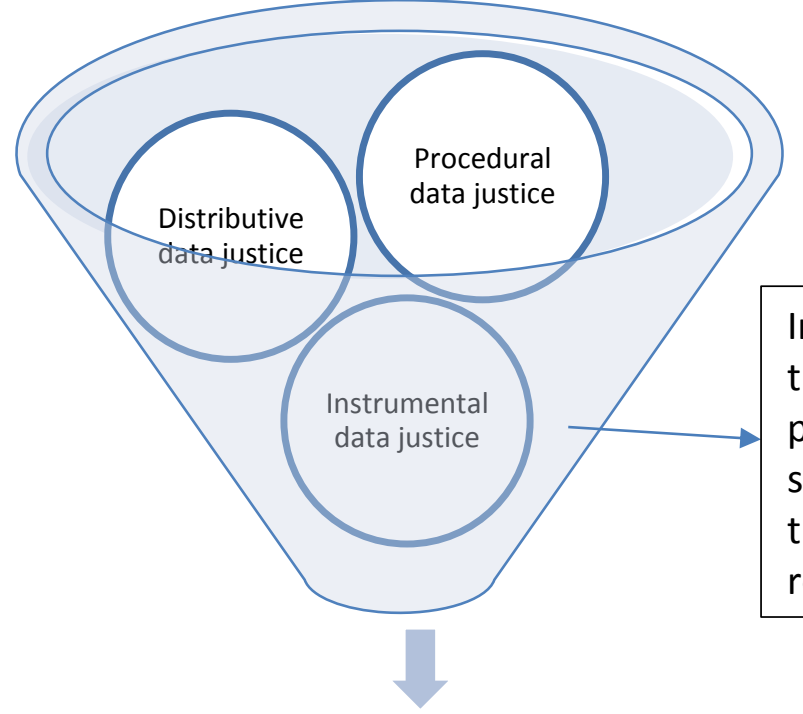

Internal power structure of the slum along with larger power structures of society manifested through state-citizen relations

\section{Information justice $\Longrightarrow$ Resource justice}

In terms of information justice, we share the concern that datafication processes and open data policies that render such communities more visible can exacerbate injustice, with potentially high costs for vulnerable groups (Raman \& Denis 2013, Johnson 2014). Once basti residents are counted and form part of a system of information, they may become more vulnerable. With eviction a very real threat, remaining invisible is often perceived as the best form of protection. As Heeks and Renken (2018) remind us, there is also a "right to be forgotten". In this context, we advocate a pragmatic as opposed to a normative stance with regard to promoting data collection activities, one that takes account of specific settings (cf. Recommendations below).

This takes on particular importance in light of the fact that the quest for invisibility is undermined by the structural nature of information and/or data justice. As Taylor argues, "the greatest burden of dataveillance (surveillance using digital methods) has always been borne by the poor" (2017: 2). We have noted the presence of surveillance cameras in the basti, near the PHC. This engenders the "ambivalence of legibility", noted by Heeks and 
Shekhar (2019:1006) -- marginalized populations want to stay hidden to avoid eviction and yet simultaneously want to be visible in order to access security, resources and services.

Despite the absence of formal property rights, we have observed a thriving informal rent economy. Residents lease out a room or two in their house to others, often migrants from other states. This rental income is a critical source of livelihood for these families, many of whom earn subsistence-level wages. There was a strong reluctance to reveal this rental economy to the gaze not only of the state but also to the putatively neutral gaze of the researcher. In fact, the most vociferous opponent of our enumeration admitted his suspicion that we would report his numerous rental premises. This somewhat more strategic, rather than survival, motive for the ambivalence of legibility may serve to nuance Heeks and Shekhar's (2019) analysis.

By drawing attention to the structural dimensions of data justice, our study contributes to a critique of mainstream views of data justice. Going beyond "justice as a set of theoretical principles" to "justice-in-practice" (Heeks \& Renken 2018:96), our case study speaks directly to the issues raised by these authors:

Why is access to data maldistributed in the global South? Why is participation in data processes unequally distributed? Why do the benefits of data systems in developing countries include some and exclude others?

We argue that broader forms of resource and distributive injustice also limit the scope for the creation of new datasets about slum communities, with potential implications for improving assets, as Heeks and Shekhar (2019) suggest. In our comparative assessment of data collection, we find that the promise of downstream impacts shapes receptivity to upstream activities to a degree but that instrumental or procedural justice approaches only go so far in allaying legitimate concerns and pervasive distrust of data collection in the presence of significant structural injustices. This is because information processes for such vulnerable populations carry material risks and are subject to significant regulation by sometimes self-styled leaders.

Our findings have ethical and methodological implications both for state and non-state data collection processes, including for researchers in such settings. Dealing with non-literate communities in a setting where structural factors shape or hinder the realization of data justice requires special precautions. It cannot be assumed that such communities will have the capabilities needed to assess the fallout of data processes. Deep mistrust, especially where previous state-condoned violence has taken place, is to be expected. Engaging community organizations or resource providers, where they exist, rather than relying on traditional leaders, may help bypass the more intractable aspects of information politics.

Our findings suggest some concrete repercussions for community mapping and data collection exercises, outlined below. 


\section{E1. Recommendations}

- Before undertaking upstream data collection activities, data collectors must map out risks and rewards for different interest groups, remaining cognizant of the ways the information landscape is splintered by caste, class, language and gender lines. In other words, understanding the interplay of information politics within the community is a key first step, especially in the absence of civil society gatekeepers/facilitators or CBOs.

- Qualitative approaches that allow for open-ended 'listening' are received better by vulnerable groups compared to quantitative surveys or more structured approaches that can often be perceived as 'extractive'. In our experience, spatialized data collection and spatial mapping, in particular, can be perceived as threatening and may lead to resistance from residents.

- State-led data collection with clearly identified downstream impact linkages such as surveys conducted by the ICDS may represent an exception to this resistance. It is still early to judge because most of these surveys were conducted before the eviction in August 2018. State-led surveyors (like those of the Indian Census) have a more direct approach and they inform the residents of the benefits of the survey upfront.

- More broadly, while demonstrating clear downstream linkages may be key to realizing the promise of the digital technology revolution for vulnerable urban populations in the global South, we argue that instrumental or procedural concerns only partially address the deeper structural factors that mediate the politics of information in these settings. Recent resistance to the digitized version of the ICDS survey highlights the ways in which mistrust is engendered by the way digital technologies are deployed in these settings. Digital data processes operate most often to make vulnerable populations visible, leaving them little scope to stake out claims to land or livelihood.

\section{E2. Future directions}

The role of socially prominent gatekeepers in the context of intra-community differentiation has received considerable interest in the methodological literature on ethnography (for example, Srinivas 1980). Employing the lens of information politics, our conceptual framework offers an approach to broaden these concerns to understand how hierarchy and disparity within the black box of the community may play out in the context of the datafication of vulnerable communities. In this paper, we have focused our attention on the ramifications of such information politics on community mapping and data collection exercises. However, our larger contention remains that information is a resource, access to which is regulated through structures of power within and outside vulnerable communities.

In future work, we aim to explore the ways in which power mediates the relationship of information access to resource access by looking at public services beyond occupational rights. In particular, access to water remains a deeply contested and potentially illuminating arena for the interplay of information/data processes with the right to the city (for the Indian context see Zérah et al 2011). Can communities expand information and resource access by adapting to the digitization agenda of the state?

In addition, while a large body of work has established the rise of spatial and institutional fragmentation in peri-urban settings, this case study suggests intriguing clues about 
emerging forms of informational fragmentation that follow and deepen socio-economic fissures in these spaces. Indeed, the salience of caste, language and gender disparities may also provide a link between informational and institutional fragmentation that underlie emerging forms of segregation in Indian cities. For example, the rise of gated communities consolidates both physical and informational barriers across caste-class divides. However, our study points to hitherto little understood forms of informational division - for example between local communities and low-skilled migrants along lines of language. Tracing the contours of these merging informational landscapes remains an important agenda for future work. 


\section{References}

Benjamin, S. (2008). Occupancy urbanism: radicalizing politics and economy beyond policy and programs. International Journal of Urban and Regional Research, 32(3), 719-729.

Benjamin, S.A. and Bhuvaneswari, R. (2001). Democracy, Inclusive Governance and Poverty in Bangalore. Birmingham, AL: University of Birmingham.

Chatterjee, P. (2004). The Politics of the Governed: Reflections on Popular Politics in Most of the World. New York, NY: Columbia University Press.

Donovan, K. (2012). Seeing like a slum: Towards open, deliberative development. Georgetown Journal of International Affairs, 13(1), 97-104.

Drèze, J., Khalid, N., Khera, R. and Somanchi, A. (2017). Aadhaar and food security in Jharkhand. Economic and Political Weekly, 52(50), 51.

Hagen, E. (2017). Open Mapping from the Ground Up: Learning from Map Kibera, Making All Voices Count Research Report. Brighton, UK: Institute of Development Studies.

Harvey, D. (2003). The right to the city. International Journal of Urban and Regional Research, 27(4), 939-941.

Heeks, R. (2017). A Structural Model and Manifesto for Data Justice for International Development, GDI Development Informatics Working Paper No.69. Manchester, UK: Centre for Development Informatics, University of Manchester.

Heeks, R. and Renken, J. (2018). Data justice for development: What would it mean? Information Development, 34(1), 90-102.

Heeks, R. and Shekhar, S. (2019). Datafication, development and marginalised urban communities: An applied data justice framework. Information, Communication and Society, 22(7), 992-1011.

Johnson, J.A. (2014). From open data to information justice. Ethics and Information Technology, 16(4), 263-274.

Krishna, S. (2019). Aadhaar-led Identification and Datafication among Informal Workers in South India: A Data Justice Perspective, Development Informatics Working Paper No. 79. Manchester, UK: Centre for Development Informatics, University of Manchester.

Lefebvre, H., 1996. Writings on Cities. Oxford, UK: Oxford University Press.

Lundine, J., Kovacic, P. and Poggiali, L. (2012). Youth and digital mapping in urban informal settlements: Lessons learned from participatory mapping processes in Mathare in Nairobi, Kenya. Children, Youth and Environments, 22(2), 214-233.

MHUPC (2015): Slums in India: A Statistical Compendium. New Delhi: Ministry of Housing and Urban Poverty Alleviation.

Panek, J. and Sobotova, L. (2015). Community mapping in urban informal settlements. Electronic Journal of Information Systems in Developing Countries, 68(1), 1-13.

Ranganathan, M. (2014). Paying for pipes, claiming citizenship: Political agency and water reforms at the urban periphery. International Journal of Urban and Regional Research, 38(2), 590-608.

Rathi, A. and Tandon, A. (2019) Capturing Gender and Class Inequities: The CCTVisation of Delhi, Development Informatics Working Paper No. 81. Manchester, UK: Centre for Development Informatics, University of Manchester.

Shekhar, S. (2012). The unequal access to municipal services and the role of local elected representatives, paper presented at N-AERIS XIII, Paris, 22-24 Nov.

Srinivas, M.N. (1980). The Remembered Village. Berkeley, CA: University of California Press. 
Taylor, L. (2017). What is data justice? The case for connecting digital rights and freedoms on the global level. Big Data and Society, 4(2), 1-14.

Zérah, M.-H., Dupont, V. and Tawa Lama-Rewal, S. (eds.). (2011). Urban Policies and the Right to the City in India. Rights, Responsibilities and Citizenship. New Delhi: UNESCO \& Centre de Sciences Humaines.

\title{
Acknowledgements
}

The "Urban Data, Inequality and Justice in the global South" case studies form part of a Senior Research Fellowship funded by the University of Manchester's Sustainable Consumption Institute with additional financial support from Canada's International Development Research Centre. The authors acknowledge their gratitude to Rajkumar Passedula and Ravi Teja Sangeetha, who assisted with the enumeration and interviews. Their deep knowledge of the field and sharp insights contributed in multiple ways to our understanding of this case. They also thank Richard Heeks for his detailed and constructive comments on previous versions of this document.

\begin{abstract}
About the Authors
Loraine Kennedy is CNRS Research Director at the Centre for South Asian Studies (CEIAS), EHESS, in Paris. Her current work, at the crossroads of political economy and political geography, examines sub-national state rescaling and metropolitan governance in India and in international comparison. Ashima Sood is Fellow at the Centre for Learning and Management Practice at the Indian School of Business, in Hyderabad. Her research lies at the intersection of institutional economics and urban and development studies. It combines qualitative and quantitative methodologies to examine the policy frameworks encouraging greenfield urban development and privatized forms of urban governance in India. Debdatta Chakraborty is a Research Editor for ISBInsight magazine at the Indian School of Business, in Hyderabad. She has completed her post-graduation in Sociology. Her research interests lie in informal labour in urban spaces. Ram Mohan Chitta is a Research Editor at the Centre for Learning and Management Practice at the Indian School of Business, in Hyderabad. His key interests are in urban sociology, digital media and critical theory.
\end{abstract}

